\title{
Development of Low Sodium Table Butter via Partial Replacement of Sodium Chloride with Potassium Chloride
}

\author{
Deepak Mudgil $1, * \mathbb{D}$, Sheweta Barak ${ }^{1(\mathbb{D})}$ \\ 1 Department of Dairy Technology, Mansinhbhai Institute of Dairy and Food Technology, Mehsana, Gujarat-384002, India \\ * Correspondence: dsmudgil@yahoo.com;
}

Scopus Author ID 51864139900

Received: 10.04.2020; Revised: 1.05.2020; Accepted: 1.05.2020; Published: 3.05.2020

\begin{abstract}
Butter is a dairy product that is trendy among consumers because of its uncommon taste and aroma. Table butter involves the addition of common salt $(\mathrm{NaCl})$ during its processing. Thus, its daily consumption leads to a high intake of sodium which is not good for health. Excessive sodium level in daily diet is associated with an increase in blood pressure of consumers which leads to certain heart disease including heart-stroke, cardiac-collapse and kidney disease. Hence, in the present study was designed to reduce the sodium content in the table butter via replacement of sodium chloride with potassium chloride. Potassium chloride not only replaces sodium but also provides the lowering of blood pressure (B.P.) in high B.P. patients. The present study reveals that low sodium butter made with potassium chloride is acceptable to consumer's w.r.t. important sensory attributes. $\mathrm{KCl}$ in table butter can replace up to $30 \%$ of sodium chloride $(\mathrm{NaCl})$ with acceptable sensory characteristics.
\end{abstract}

Keywords: Butter; table salt; low-sodium; dairy product; sensory acceptability.

(C) 2020 by the authors. This article is an open access article distributed under the terms and conditions of the Creative Commons Attribution (CC BY) license (https://creativecommons.org/licenses/by/4.0/).

\section{Introduction}

Milk is considered a very necessary and fundamental source of nutrients [1]. Liquid milk and products prepared from milk are very much liked by consumers of all ages [2-3]. Many of the fat-rich dairy products (including butter) are used as fundamental ingredients in various dishes or products [4-8]. Recent trends in dairy and food research suggest that scientists are more targeted to develop dairy and food products with some value addition and functional application [9-21]. Butter is one of the main products of dairy industry which contribute good share in dairy products market because of its appealing taste and aroma. Butter is prepared from ripened and chilled cream via churning process. Butter grains are separated from buttermilk during churning process and are subjected to washing and working operations to get the finished butter. Depending on the addition of table salt in butter making; butter can be categorized into two types: white butter \& table butter. White butter is the type of butter that is prepared from the cream without the addition of table salt $(\mathrm{NaCl})$ whereas table butter involves addition of table salt $(\mathrm{NaCl})$ at the rate of $2-3 \%$ in its production process. Sodium chloride $(\mathrm{NaCl})$ is an important and crucial ingredient of table butter which is mainly responsible for its characteristic flavor and it also controls microbial growth in butter. It gets solubilized in the water content present in the table butter and distributed throughout the butter body for uniform taste via working of butter. It can cause problems if the working of butter is not proper as it can cause precipitation of curd present in butter. Table salt can also decrease the water-holding ability of table butter as it aids in the formation of big water droplets which leads to leaky body 
of table butter. Hence, proper working of table butter is required to prevent the leakage or syneresis of water from table butter.

In human body, sodium perform crucial role in controlling the osmotic balance. It also helps in maintaining optimum functions of nerves. If a person increases the levels of sodium in his/her daily diet it will lead to an increase in blood pressure which further may enormously enhance the danger of heart-stroke, cardiac-collapse and certain diseases related to kidneys. Reduction in the sodium content of diet is considered to have potential influence on reduction of blood pressure of selected human population. That is why the requirements or market demand for low-sodium dairy and food products are rising day-by-day to decrease the levels of sodium intake in daily diet [22-23]. Addition of up to $3 \%$ sodium chloride is allowed in table butter making. Generally $2.5 \% \mathrm{NaCl}$ is added in table butter by butter manufacturers. A high intake of sodium could lead to an increase in blood pressure. There are several ways for reducing sodium chloride content in food products. One of the methods is a replacement of sodium chloride in food products with other chemicals that exhibit identical saltiness on consumption of these food products. Partial substitution of sodium chloride with potassium chloride $(\mathrm{KCl})$ is an easy and preferable method for reducing sodium levels in dairy products [24]. It has been tried in various types of cheeses. Potassium chloride cannot completely replace $\mathrm{NaCl}$ in dairy products because it is associated with some defects in end products such as bitterness, metallic flavor and some textural variations [25]. Hence, only $30 \%$ of sodium chloride replacement with potassium chloride has been recommended. Above this level, it produces prominent undesirable flavor in the product which is not accepted by consumers. Hence it is recommended to partially substitute $\mathrm{NaCl}$ with $\mathrm{KCl}$ and added to the products in blended form [22]. No research study has been reported in the literature related to the development of low sodium butter by replacement of $\mathrm{NaCl}$ with $\mathrm{KCl}$ till date. Hence, the present research study was taken up to develop low sodium butter by partial replacement of common salt and to characterize physicochemical properties of low-sodium butter.

\section{Materials and Methods}

\subsection{Materials.}

Cream, skim milk, table salt and annatto color samples were made available by Dudhsagar Dairy, Mehsana, and rest of the chemical used in the analysis were of analytical grade and were procured from Sigma Chemicals (India).

\subsection{Preparation of control table butter.}

The control butter sample was prepared using cream standardized for $40 \%$ fat content. This standardized cream was then subjected to pasteurization at $80^{\circ} \mathrm{C}$ for 25 seconds. This pasteurized cream was then cooled and stored at $5{ }^{\circ} \mathrm{C}$ for $12 \mathrm{~h}$, and churning of cream was then carried out at $8{ }^{\circ} \mathrm{C}$ in planetary stand mixer. After phase inversion and formation of butter grains, buttermilk was separated, and the grains were washed with pasteurized chilled water ( 8 ${ }^{\circ} \mathrm{C}$ ). After removal of wash water, $2.5 \%$ refined table salt (sodium chloride) was added, followed by kneading for about 8 min for joining butter grains and eliminating the remaining water. The required quantity of water and color was added to butter and the final moisture content of $16 \%$ was achieved. This was referred to as 'control butter' $\left(\mathrm{T}_{1}\right)$ in this study.

\subsection{Preparation of low sodium table butter.}


For the preparation of low sodium butter samples, the sodium chloride was replaced with potassium chloride at the rate of $10 \%, 20 \%, 30 \%$ and $40 \%$ levels on weight basis and was designated as $\mathrm{T}_{2}, \mathrm{~T}_{3}, \mathrm{~T}_{4} \& \mathrm{~T}_{5}$ butter samples, respectively. The quantity of annatto color added to butter samples was similar to control butter. The butter samples were placed in plastic containers and stored under refrigeration $\left(10^{\circ} \mathrm{C}\right)$ for further analysis.

\subsection{Analysis of control and low sodium butter.}

Control butter sample and low sodium butter samples were analyzed for moisture content, salt content, curd/SNF content and fat content using AOAC standard methods of analysis (1995). Color of the samples was measured using colorimeter (Konica Minolta).

\subsection{Sensory Evaluation.}

Control table butter and low-sodium table butter samples were also evaluated for their sensory characteristics using 9-points hedonic scale. Sensory evaluation was conducted by twenty five sensory judges who were selected on the basis of knowledge and previous experiences of sensory evaluation of butter samples. The sensory attributes selected for scoring were color and appearance of butter, flavor of butter, body and texture of butter and overall acceptability of butter samples. Refrigerated butter samples having approximately $10^{\circ} \mathrm{C}$ temperature were given to sensory judges in irregular order. Containers used for serving butter samples to sensory panelists were also coded for unbiased sensory scores. Necessary things such as mouth-rinse water and spitting pan were also provided to sensory judges during the evaluation sessions.

\section{Results and Discussion}

\subsection{Physico-chemical Analysis.}

Results obtained from the analysis of control and low sodium butter reveals that there were no significant differences between the values obtained for moisture content, salt content, curd/SNF content, fat content and color values of control and low sodium butter (Table 1).

Table 1. Analysis of control and low-sodium butter.

\begin{tabular}{l|l|l|l|l|l} 
Butter Samples & $\mathbf{T}_{\mathbf{1}}$ & $\mathbf{T}_{\mathbf{2}}$ & $\mathbf{T}_{\mathbf{3}}$ & $\mathbf{T}_{\mathbf{4}}$ & $\mathbf{T}_{\mathbf{5}}$ \\
\hline Moisture \% & 15.91 & 16.32 & 16.35 & 16.31 & 16.16 \\
\hline Salt \% & 2.25 & 2.27 & 2.30 & 2.31 & 2.29 \\
\hline Curd \% & 1.46 & 1.47 & 1.51 & 1.51 & 1.51 \\
\hline Fat \% & 80.13 & 79.90 & 79.80 & 79.95 & 80.05 \\
\hline Color (Yellowness & 48.00 & 48.35 & 48.30 & 48.35 & 48.45
\end{tabular}

Note: Results are average values of determinations made in triplicate

$\mathbf{T}_{1}$ - control butter; $\mathbf{T}_{2}$ - butter with $10 \% \mathrm{NaCl}$ replacement;

$\mathbf{T}_{3}$ - butter with $20 \% \mathrm{NaCl}$ replacement;

T4- butter with $30 \% \mathrm{NaCl}$ replacement;

$\mathbf{T}_{\mathbf{5}}$ - butter with $40 \% \mathrm{NaCl}$ replacement

The moisture of the butter samples ranged from 15.91 to $16.35 \%$. Control butter sample exhibited the lowest moisture content i.e. $15.91 \%$. All the butter samples having $\mathrm{NaCl}$ replaced with $\mathrm{KCl}$ exhibited slightly more moisture content as compared to control butter sample. Salt content was determined using titration with $\mathrm{AgNo}_{3}$ solution which only reacts with chloride and reveals the salt content of butter samples. Salt content of butter samples ranged from $2.25 \%$ 
to $2.31 \%$. $\mathrm{T}_{4}$ butter sample was having the highest salt content. Curd content of all the butter samples was almost similar and were ranged from $1.46 \%$ to $1.51 \%$. Curd content of butter represents the SNF content in the butter. Fat content of butter samples ranged from $79.80 \%$ to $80.13 \%$. Replacement of $\mathrm{NaCl}$ with $\mathrm{KCl}$ did not affect the color of the butter samples however butter samples containing $\mathrm{KCl}$ showed more yellowness with respect to control butter sample (Figure 1).

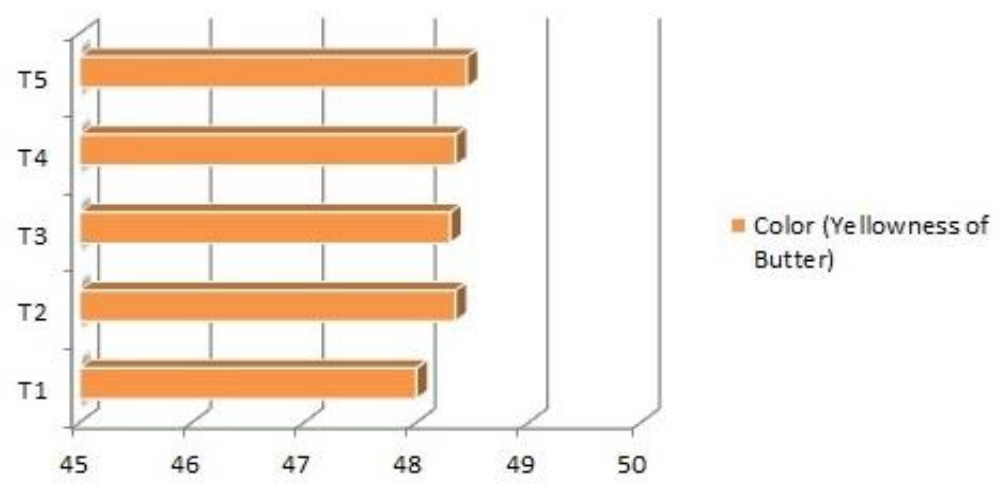

Figure 1. Effect of $\mathrm{NaCl}$ replacement with $\mathrm{KCl}$ on the color (yellowness) of butter samples.

\subsection{Sensory Evaluation.}

Sensory properties are very significant from consumer view point [26-27].In contrast to the physicochemical analysis of control and low sodium butter, sensory evaluation results showed significant differences among sensory attributes. It reveals that the replacement of sodium chloride with potassium chloride in table butter influences sensory parameters (Table 2).

Table 2. Sensory evaluation of control and low sodium butter.

\begin{tabular}{l|l|l|l|l|l}
\hline Butter Samples & $\mathbf{T}_{\mathbf{1}}$ & $\mathbf{T}_{\mathbf{2}}$ & $\mathbf{T}_{\mathbf{3}}$ & $\mathbf{T}_{\mathbf{4}}$ & $\mathbf{T}_{\mathbf{5}}$ \\
\hline Color \& Appearance & 7.16 & 7.16 & 7.12 & 7.10 & 7.03 \\
\hline Body and Texture & 6.83 & 6.83 & 6.83 & 6.67 & 6.64 \\
\hline Flavor & 6.56 & 6.42 & 6.39 & 6.27 & 5.67 \\
\hline Overall Acceptability & 6.79 & 6.78 & 6.73 & 6.72 & 6.32
\end{tabular}

Note: Results are average values of scores obtained from 25 sensory panelists

$\mathbf{T}_{1}$ - control butter; $\mathbf{T}_{2}$ - butter with $10 \% \mathrm{NaCl}$ replacement;

T3- butter with $20 \% \mathrm{NaCl}$ replacement;

T4- butter with $30 \% \mathrm{NaCl}$ replacement;

$\mathbf{T}_{\mathbf{5}}$ - butter with $40 \% \mathrm{NaCl}$ replacement

Scores for color and appearance of butter samples were ranged from 7.03 to 7.16. Butter samples with $10 \%$ replacement showed similar scores for color and appearance as compared to control (Figure 2). The lowest score for color and appearance was observed for $\mathrm{T}_{5}$ sample. However, the change was very slight. Sensory scores for body and texture was the same for control, $\mathrm{T}_{1}$ and $\mathrm{T}_{2}$ butter samples. However, $\mathrm{T}_{4}$ and $\mathrm{T}_{5}$ butter samples showed somewhat lower scores as compared to control (Figure 2). The main difference in sensory score was observed for flavor attribute of butter sample which mainly describes the acceptability of the low-sodium table butter. The sensory scores for flavor of butter sample decreased with an increase in the replacement level of $\mathrm{NaCl}$ with $\mathrm{KCl}$ (Figure 3). 


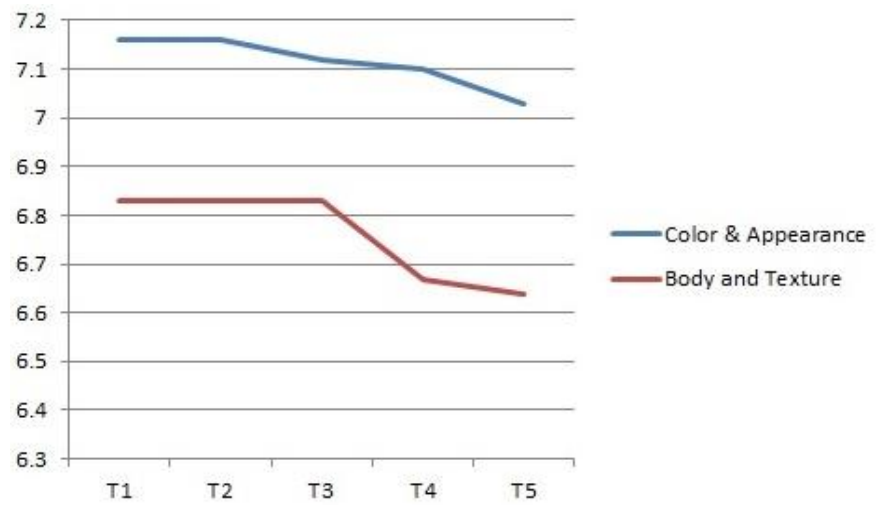

Figure 2. Effect of $\mathrm{NaCl}$ replacement with $\mathrm{KCl}$ on the color \& appearance and body \& texture of butter samples.

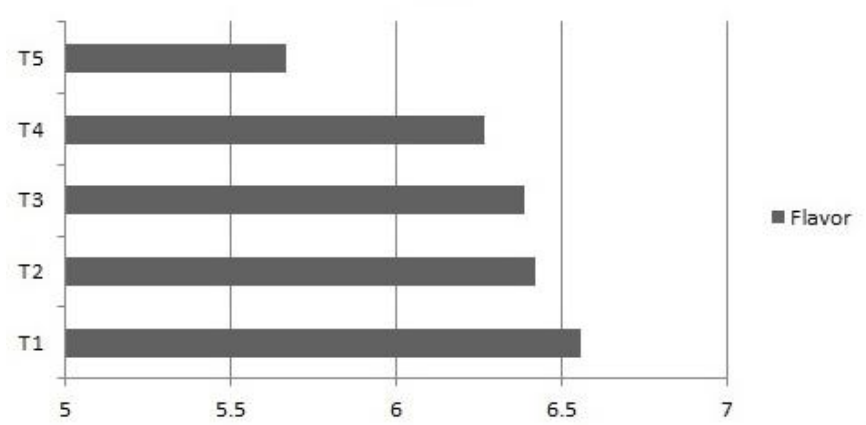

Figure 3. Effect of $\mathrm{NaCl}$ replacement with $\mathrm{KCl}$ on the flavor of butter samples.

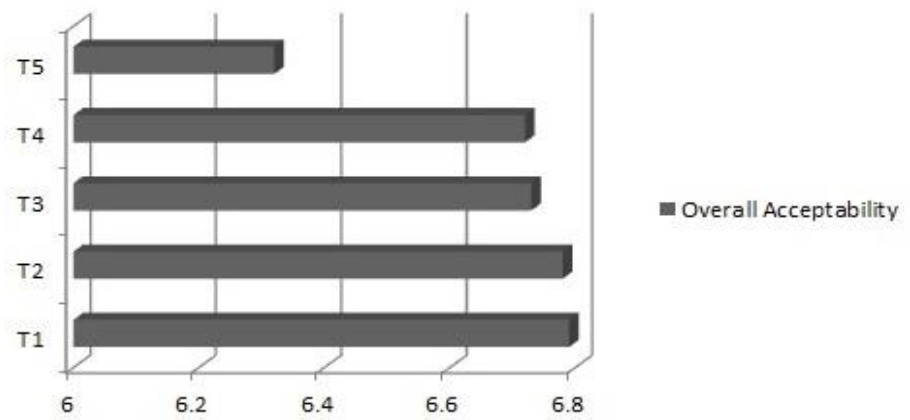

Figure 4. Effect of $\mathrm{NaCl}$ replacement with $\mathrm{KCl}$ on the overall acceptability of butter samples.

Control butter sample showed the highest flavor score whereas $\mathrm{T}_{5}$ butter samples exhibited the lowest score for flavor. Results reveal that $\mathrm{NaCl}$ replacement up to $30 \%$ ( $\mathrm{T}_{4}$ Sample) was accepted by sensory panelists and beyond that level bitter metallic flavor was reported by the sensory panelists. Overall acceptability of the butter samples ranged from 6.79 to 6.32. Control butter sample was the most accepted sample whereas $T_{5}$ butter sample was the least accepted butter sample. Overall acceptability results also suggest that $\mathrm{T}_{4}$ Sample was acceptable by consumer with a little lower score as compared to control butter sample with no replacement of $\mathrm{NaCl}$ with $\mathrm{KCl}$ (Figure 4).

\section{Conclusions}

It is concluded from the research that the sodium chloride in table butter can be replaced with potassium chloride at 20-30\% level. However, some panelists observe slight bitter and pronounced salty flavor in the butter samples containing potassium chloride higher than $30 \%$ concentration. Beyond this concentration the butter samples show poor acceptability. It is recommended that some flavoring compounds may be added to low-sodium butter containing 
potassium chloride to mask this bitter and pronounced salty flavor at a higher levels of $\mathrm{KCl}$. Hence, it is concluded that low-sodium table butter can be produced with partial replacement of sodium chloride with potassium chloride without sacrificing the organoleptic properties of the table butter.

\section{Funding}

This research received no external funding.

\section{Acknowledgments}

Authors acknowledge Executive Director of Mansinhbhai Institute of Dairy \& Food Technology, Mehsana for providing facilities for this research work \& Managing Director of Dudhsagar Dairy, Mehsana for providing samples for this study.

\section{Conflicts of Interest}

The authors declare no conflict of interest.

\section{References}

1. Mudgil, D.; Barak, S. Synthetic milk: a threat to Indian dairy industry. Carpathian Journal of Food Science \& Technology 2013, 5, 64-68.

2. Mudgil, D.; Barak, S. Development of functional buttermilk by soluble fibre fortification. Agro Food Industry Hi Tech 2016, 27, 44-47.

3. Mudgil, D.; Barak, S. Beverages: Processing and technology. $1^{\text {st }}$ ed.; Scientific Publishers, Jodhpur, India, 2018; pp. 1-16.

4. Soundous, E.H.; Amaury, G.; Juliette, D.; Sybille, D.; Aurélie, L.; Viviane, P.; Marianne, S. Overview of the local production process of raw milk butter in Wallonia (Belgium). International Journal of Dairy Technology 2019, 72, https://doi.org/10.1111/1471-0307.12608.

5. Song, Y.; Li, X.; Zhong, Y. Optimization of butter, xylitol, and high-amylose maize flour on developing a low-sugar cookie. Food Science \& Nutrition 2019, 7, 3414-3424, https://doi.org/10.1002/fsn3.1160.

6. Kumari, P.; Kadyan, M.S.; Kumar, J. Profit analysis of butter-oil (ghee) producing system of milk plant using supplementary variable technique. International Journal of System Assurance Engineering and Management 2019, 10, 1627-1638, https://doi.org/10.1007/s13198-019-00913-7.

7. Berger, R. Clarified Commodities: Managing Ghee in Interwar India. Technology and Culture 2019, 60, 1004-1026, https://doi.org/10.1353/tech.2019.0099.

8. Górska-Warsewicz, H.; Rejman, K.; Laskowski, W.; Czeczotko, M. Butter, Margarine, Vegetable Oils, and Olive Oil in the Average Polish Diet. Nutrients 2019, 11, 2935, https://doi.org/10.3390/nu11122935.

9. Jariyah; Yektiningsih, E.; Sarofa, U. Evaluation of antidiabetic and anticholesterol properties of biscuit product with mangrove fruit flour (mff) substitution. Carpathian Journal of Food Science \& Technology 2019, 11, 141-152, https://doi.org/10.34302/2019.11.4.13

10. Mudgil, D.; Barak, S.; Khatkar, B.S. Development of functional yoghurt via soluble fiber fortification utilizing enzymatically hydrolyzed guar gum. Food Bioscience 2016, 14, 28-33, https://doi.org/10.1016/j.fbio.2016.02.003.

11. Menasra, A.; Fahloul, D. Quality characteristics of biscuit prepared from wheat and milk thistle seeds (silybum marianum (1) gaertn) flour. Carpathian Journal of Food Science \& Technology 2019, 11, 5-19, https://doi.org/10.34302/crpjfst/2019.11.4.1

12. Mudgil, D.; Barak, S.; Darji, P. Development and characterization of functional cultured buttermilk utilizing Aloe vera juice. Food Bioscience 2016, 15, 105-109, https://doi.org/10.1016/j.fbio.2016.06.001.

13. Jalali, M.; Sheikholeslami, Z.; Elhamirad, A.H.; Khodaparast, M.H.H.; Karimi, M. The effect of balangu shirazi (lallemantia royleana) gum on the quality of gluten-free pan bread containing pre-gelatinized simple corn flour with microwave. Carpathian Journal of Food Science \& Technology 2019, 11, 68-83, https://doi.org/10.34302/crpjfst/2019.11.2.6

14. Mudgil, D. The Interaction Between Insoluble and Soluble Fiber. In: Dietary Fiber for the Prevention of Cardiovascular Disease. Samaan, R.A. Eds.: Academic Press: Los Angeles, USA. 2017; pp. 35-59, https://doi.org/10.1016/B978-0-12-805130-6.00003-3

15. Zhu, F.; Prosser, C.; Zhu, Y.; Otter, D.; Hemar, Y. Enzymatic formation of galactooligosaccharides in goat milk. Food Bioscience 2018, 26, 38-41, https://doi.org/10.1016/j.fbio.2018.09.005 
16. Mudgil, D.; Barak, S.; Khatkar, B.S. Texture profile analysis of yogurt as influenced by partially hydrolyzed guar gum and process variables. Journal of Food Science and Technology 2017, 54, 3810-3817. https://doi.org/10.1007/s13197-017-2779-1

17. Mohanty, D.; Misra, S.; Mohapatra, S.; Sahu, P.S. Prebiotics and synbiotics: Recent concepts in nutrition. Food Bioscience 2018, 26, 152-160, https://doi.org/10.1016/j.fbio.2018.10.008

18. Mudgil, D. Influence of partially hydrolyzed guar gum as soluble fiber on physicochemical, textural and sensory characteristics of yoghurt. Journal of Microbiology, Biotechnology and Food Sciences 2018, 8, 794797.

19. Suryawanshi, V.; Sakarkar, S.; Kaur, D.C.D.; Sarwa, K. Characterization of Thermal Fraction of Clarified Butter and its Applicability to Improve Bioavailability of Rosuvastatin. Indian Journal of Pharmaceutical Education and Research 2019, 53, 716-723, https://doi.org/10.5530/ijper.53.4.136.

20. Mudgil, D.; Barak, S. Dairy-Based Functional Beverages. In: Milk-Based Beverages. Grumezescu ,A.M.; Maria, A. Eds.: Woodhead Publishing, Elsevier, USA. 2019; pp. 67-93, https://doi.org/10.1016/B978-0-12815504-2.00003-7

21. Mudgil, D.; Barak, S. Classification, Technological Properties, and Sustainable Sources. In:p Dietary Fiber: Properties, Recovery, and Applications. Galankis, C.M. Eds.: Academic Press: Los Angeles, USA. 2019b; pp. 27-58, https://doi.org/10.1016/B978-0-12-816495-2.00002-2

22. Akan, E.; Yerlikaya, O.; Kinik, O. Importance of salt in dairy products and sodium reduction strategies in food and dairy products. Agro Food Ind Hi Tech 2017, 28, 60-62.

23. Mudgil, D.; Barak, S. Functional Foods: Sources and Health Benefits. $1^{\text {st }}$ ed.; Scientific Publishers, Jodhpur, India, 2017; pp. 1-16.

24. Gomes, A.P.; Cruz, A.G.; Cadena, R.S.; Celeghini, R.M.S.; Faria, J.A.F.; Bolini, H.M.A., Pollonio, M.A.R.; Granato, D. (2011). Manufacture of low-sodium Minas fresh cheese: Effect of the partial replacement of sodium chloride with potassium chloride. Journal of Dairy Science 2011, 94, 2701-2706, https://doi.org/10.3168/jds.2010-3774

25. Cruz, A. G.; Faria, J.A.; Pollonio, M.A.; Bolini, H. M.; Celeghini, R.M.; Granato, D.; Shah, N.P. Cheeses with reduced sodium content: Effects on functionality, public health benefits and sensory properties. Trends in Food Science \& Technology 2011, 22, 276-291, https://doi.org/10.1016/j.tifs.2011.02.003

26. Mudgil, D.; Barak, S.; Khatkar, B.S. Soluble fibre and cookie quality. Agro Food Industry Hi Tech, 2012, $23,15-17$.

27. Mudgil, D.; Barak, S.; Khatkar, B.S. Cookie texture, spread ratio and sensory acceptability of cookies as a function of soluble dietary fiber, baking time and different water levels. LWT-Food Science and Technology, 2017, 80, 537-542, https://doi.org/10.1016/j.lwt.2017.03.009. 